\title{
Letter from the Editor: A Defining Moment in the History of Borders
}

\author{
SUSAN BARBER
}

Simon Fraser University

Welcome to the inaugural issue of the SFU Educational Review, a peer-reviewed online journal of Simon Fraser University's Faculty of Education. Dedicated specifically to exploring the possibilities that arise when disciplinary boundaries are removed, this annual publication is a proud showcase of a diverse body of work emerging from the Education With/Out Borders Symposium, the Education Graduate Student Association (EGSA) annual conference held at Sasamat, British Columbia.

It is not often that an editor has the honour of inaugurating a new journal, online or otherwise. At the beginning, our editorial team sensed there was a slight hint of destiny about it, but as the tasks became more detailed and we focused on deadlines and complexities, the feeling took on other dimensions. And yet, it was here at the end, when the galleys suddenly leapt onto the screen, the templates having coaxed texts into a uniform and official appearance, that the final published reality returned us more forcefully to the sense of making history.

This "history" of course has a history. The published work that you are now viewing was an outgrowth of an idea that arose two years ago when it was suggested to the Faculty of Education that we start an e-press, or electronic press. Mark Weiler spoke to Johanne Provençal about drawing up a proposal that would be presented to our Dean, Dr. Paul Shaker. After much discussion, Dr. Tom O'Shea, Director of Graduate Programs, fine-tuned the proposal's parameters, and along with the Assistant to the Director, Karen Kirkland's support, the e-press was then tied to the annual EGSA-organized graduate student conference with funding secured for three years by the Dean's office. With help from the SFU library in setting up a journal through OJS, the Open Journal System, we were ready to survey the conference presenters at Sasamat to find out who would be interested in having their papers peer-reviewed, peer-edited and published. After the conference itself, Calls for Art, Reviewers and Submissions were made. As the calendar clicked over to 2007, the peer review began and continued until the manuscripts became journal articles. It cannot be emphasized enough how much this new journal has been a collaborative effort.

As Editor, I am deeply indebted to our Project Manager, Johanne Provençal, for her exceptional effort at keeping watch over the whole process and ensuring its success. With her extensive experience in publishing, she has navigated the major hurdles that arise in starting a journal from scratch and has crossed numerous borders of her own job description in order to maintain the journal's mandate. I would also like to thank Carl Forde, our Web Designer, for bringing his expertise to bear on "the look" of our pages, not only in displaying our beautiful works of art to their greatest aesthetic advantage, but also for ensuring our online presence was compatible with the OJS system as well as the Internet community. For the initial set up and technical advice, our gratitude goes to Kevin Stranack, Brian Owen and Mark Jordan at the SFU library, as well as Mark Weiler for his production at our official launch.

(C) Copyright 2007. The author, Susan Barber, assigns to the SFU Educational Review the right of first publication and educational and non-profit institutions a non-exclusive license to use this document for personal use and in courses of instruction provided that the article is used in full and this copyright statement is reproduced. Any other usage is probibited without the express permission of the author. 
Many thanks also go to our artists, Gerda van de Windt and Zuzana Vasko, who give our visitors a strong first impression. I hope you will be as impressed as we were with the quality of their work. Quality is very much on the mind of any editorial team and our journal had some particular decisions to make about how to review works that we specifically requested to be creative and transgress the usual disciplinary lines. How to guide reviewers who were asked to keep an open and flexible mind when engaging with nontraditional works or innovative approaches, while judging the level of scholarship and significance to the field? To complicate things, there were also issues around respecting disciplinary differences, which can include style, vocabulary and even language usage. The reviewing and editing processes must not distort the integrity of the authors' intentions for their pieces and that often means finding the right compromise. Not a simple undertaking. Good reviewers make an editor's job much easier and I would like to thank the following people for their time, knowledge and critical abilities in bringing the texts up to their current level of quality: Dr. Ann Chinnery, Dr. Catherine McGregor, Karyn Audet, Marc Berezowski, Carl Forde, Jan MacLean, Jana Milloy, Craig Newell, Johanne Provençal, and Mark Weiler.

In engaging with these texts, I have had the pleasure of considering some of their most pressing questions. For instance, what if we could discover through neuroscience research how students learn best, emotionally, cognitively, environmentally and so on? With the sophistication of technology that we now possess, what if we could bring together researchers from education, neuroscience, psychology, kinesiology, mathematics, phenomenology, computing science, artificial intelligence and even Zen gardeners to make the most of this technology's potential for these fields? The implications for identifying brain states which are most conducive to improving memory, recall, concentration and forms of reasoning is beyond our current understanding. Dr. Stephen R. Campbell and the ENL group's educational neuroscience research laboratory, the ENGRAMMETRON, is unique in Canada, if not the world - it is just that new.

What if we took that idea and put another spin on it, and asked: are the conditions of learning as important as what is learned itself? In meditating upon the philosophy of Foucault, how can we determine if his vision of the "inquisitive thinker" resonates today in education? In the case of teacher education, are there rigid structures in place that limit or redirect growth, or is there still a space for Foucault's sense of exploration and play that are allowed into a learner's experiences? Dr. Heesoon Bai, Hartley Banack and Catherine Broom invite us into their conversation where they attempt to tease out these complex ideas.

This seems to lead to another fascinating question raised in Zuzana Vasko's paper: is perhaps art an antidote to escaping the instrumentalism of the postmodern era, one that will return us to our authentic selves? Are we in danger of being trampled by the frenetic pace of life, which art, with its humanizing characteristics, can help us overcome? Zuzana defends a view that arts education can go a long way towards fostering a vital connection with other people, our culture and ourselves.

This idea presupposes "bridges," which suggests another question pertinent to education: if we are to find new and useful ways to teach curriculum, where shall we begin to overcome the often conflicting views of theorists? If we take social studies as an example, is it possible to reconcile the industrial age approach, which aimed to turn out "morally upright citizens," with the progressivists' view of helping students understand their world and improving their opportunities? Catherine Broom outlines how social studies has evolved as a discipline and what it looks like today in Canada.

The questions Lorna Ramsay's exquisite photo/essay/poem raise are about learning itself. How does a child who is different situate herself in the world? How does a teacher come to trust that she will find the right pedagogy for her student? How large a part does the "ineffable" play in coming to certain understandings, both conscious and unconscious? This non-traditional piece of work accomplishes the rare effect of being able to capture a teacher-student relationship as well as somehow allowing us, through visual and literary impressions, to experience a part of it for ourselves.

I have chosen but a few of the rich ideas developed here by our authors and I invite you to read and think deeply on them. There is a sense that the crossing of borders is more significant than most of us originally realized and that it may be one of the most prominent and profound defining factors of the times we live in. Again, my sincere thanks for the hard work a number of people have done to help bring this first issue to publication. May there be many more! 